\title{
Performance of Tannin/Glycerol-Chromate Hybrid Conversion Coating on Aluminium
}

\author{
Makanjuola Oki \\ Department of Mechanical Engineering, Landmark University, Omu-Aran, Nigeria \\ Email: makanjuolaoki@gmail.com
}

Received 18 April 2015; accepted 8 June 2015; published 11 June 2015

Copyright ( 2015 by author and Scientific Research Publishing Inc.

This work is licensed under the Creative Commons Attribution International License (CC BY). http://creativecommons.org/licenses/by/4.0/

(c) () Open Access

\begin{abstract}
A smart hybrid conversion coating has been developed. Modifications of coating solutions with poly-hydroxyl organic materials to reduce the usual mud cracking pattern characteristics of chromate conversion coatings (CCCs) and improve its ability to release inhibitors to corroding sites have been achieved. The smart functionalised chromate conversion coating (SFCCC), developed on aluminium substrate has undergone laboratory checks and commercial runs under factory conditions confirmed its potency in improving corrosion resistance and paint adhesion to metal surfaces. In-service performance of the coating in the past three years is excellent.
\end{abstract}

\section{Keywords}

Adhesion, Aluminium, Aviation, Chromate Conversion Coatings, Smart Functionalised Chromate Conversion Coatings (SFCCCs)

\section{Introduction}

Corrosion is devastating to metals and alloys as well as other materials of construction, using the broad definition of corrosion as degradation of materials by chemical and/or electrochemical reactions. Most metals and alloys are electrically conducting; hence their aqueous corrosion involves electronic and ionic movements in the metal and electrolyte respectively. Thus aqueous corrosion of this set of materials is electrochemical in nature. Various methods can be employed to mitigate against corrosion. These include the use of inhibitors, paints, cathodic protection, engineering coatings such as chromate conversion coatings etc.

Conversion coatings are usually employed in the metal finishing industries to improve corrosion resistance of the underlying substrate in addition to improvement in adhesion of subsequently applied organic finishes. Chromate conversion coating combines ease of application with excellent service performance hence its popularity in the high safety ends of the metal finishing industry such as the aviation and roofing industries. 
There are inorganic and organic inhibitors. Examples of inorganic inhibitors are the silicates, chromates, phosphates etc.; while some organic inhibitors are long chained amines and their derivatives. Organic compounds which possess oxygen and sulphur atoms in their structures are eminent candidates as well because they contain electron rich centres through which they can adsorb to corroding metal surfaces where they retard corrosion reactions in one manner or the other. Other researchers [1] [2], have employed the extracts of roots, leaves and seeds of various plants as corrosion inhibitors with varying degrees of success and performance. Inhibition efficiencies obtained ranged from $70 \%$ to $98 \%$ in some instances. However, many of these recipes have not been commercialised. This may be due to various reasons ranging from difficulty in establishing patent rights to inability to convince multinationals to try such inhibitors at their sites in the developing world. In the past, Oki et al. [1] as well as Otaigbe [3], epoxidised various oil seed extracts and grafted amine on it for use as inhibitor. The inhibitor from Jatropha seed oil performed at an inhibition efficiency of about 85\%. Also tannin and hydroxyl groups containing compounds were employed as inhibitors by this author and co-workers [4] [5] and several others [6] [7] with very good performances. Tannins contain an array of hydroxyl groups and can retard the corrosion reactions of metals by adsorbing on their surfaces through the electron rich oxygen atoms in their structures. Researchers are currently making significant efforts in finding alternatives to chromate conversion coatings as a result of its toxicity. However, sol-gel coatings which have been projected as substitutes to chromate conversion coatings have been found useful in terms of improved paint adhesion capabilities whereas their corrosion prevention has been found to be inferior to those of chromates. In order to improve on this expected property, inhibitors are incorporated directly into the sol-gel matrix but often lead to detrimental properties as a result of rapid loss in their activities [8]. Other researchers [9] [10] have patented alternatives to conversion coatings in which small additions of organofunctional silanes to coating primers eliminate the use of pretreatments such as chromating or phosphating procedures. Of particular interest in prevention of corrosion in coil and aerospace aluminium or hot-dip galvanized or galvalume coil stocks is the patent by Boocock [11] which comprises of nonchromate, and highly crystalline hydrotalcite inhibitor of decavanadate ion origin. The composition which is derived from high temperature reactions among mixtures of zinc oxides/hydroxides with aluminum hydroxides and vanadium oxide is said to be effective in providing blister-free corrosion prevention in coated aluminium and its alloys.

Other recent developments in the conversion coatings world are efforts in the total replacement of chromate in conversion coating formulations and processes. However, without chromates improvement in corrosion resistance is limited [12]. Thus, the present study was designed to solve the challenges involved with $\mathrm{Cr}^{6+}$ effluents $^{\mathrm{f}}$ generated from the use of chromate in addition to promoting the efficiency in stifling corrosion reactions at breached regions of the coating where the substrates must have been exposed to the environment. Therefore, the final rinse with copious amount of water after chromating procedure was the target for elimination. $\mathrm{Thus}^{\mathrm{C}} \mathrm{Cr}^{6+}$, hitherto in the effluent which needed to be treated at a cost was removed from the processing procedure. In addition, the danger posed by $\mathrm{Cr}^{6+}$ coming in contact with workers at this stage of processing was completely eliminated.

An initial study made was in the replacements of cyanide, hitherto being used as coating accelerator, and partial replacement of chromates from pre-treatment coating formulation with phosphates. With this type of pretreatment coating, a final rinse with copious amount of water is necessary. With added cost of effluent treatment and the implication of chromate as being carcinogenic, its continued application was adversely limited. Thus, this led to the development of non-rinse coatings based on sol-gel film formation by functionalisation of inorganic species with organic moieties. Siloxanes and others have been reported to improve paint adhesion but corrosion resistance is below that of the chromate. Some mixtures of corrosion inhibitors have synergetic effects when present in a corroding system. They compliment each other in reducing corrosion rates of metals. Hence, tests conducted with tannin as corrosion inhibitor for mild steel in acid solutions gave efficiency of $72 \%$ at a concentration of 140ppm, while phosphoric acid gave 55\% and tannin/phosphoric acid gave $61 \%$ efficiency with a resultant bluish/black coating on the metal surface [4]. Next, experiments using a mixture of chromic acid and tannin showed an increase in inhibition efficiency with the formation of a reddish/brown coating on the metal surface. This is the foundation of the formulation of a fast drying non-rinse pre-treatment coating of enormous corrosion protection and good paint adhesion values. Tannins have an array of hydroxyl groups. Thus other eminently qualified candidates are poly hydroxyl compounds, such as glycerol.

Other applications of this conversion coating are in the pipeline coating industry. It is usual practice to grit blast mild steel surfaces to remove mill scales etc. prior to coating applications. A grit blasted surface is very 
reactive. It is therefore necessary to apply this non-rinse formulation to arrest flash rusting prior to application of top coats of paints.

\section{Procedure}

An alkylated or arrylated aqueous solution for depositing a mixed organic/inorganic corrosion resistant coating with self-healing properties on a metal substrate of the present study comprises: 1) a film-forming agent comprising a chromate salt and /or chromic acid that forms good paint adhesion and corrosion resistant coating at a fast rate; 2) a substrate activator adapted to remove oxides on the metal substrate prior to formation of the corrosion resistant coating; 3) an organic compound with multiple hydroxyl groups to functionalize the inorganic components; 4) a source of silicate to enhance drying. The aqueous solution has a $\mathrm{pH}$ in the range of from about 1 to about 2. Coatings were formed on $50 \mathrm{~mm} \times 100 \mathrm{~mm} \times 2 \mathrm{~mm}$ aluminium sheet stock. Prior to coating applications, all samples were washed with an alkaline degreaser solution rinsed in water and desmutted in $50 \% \mathrm{v} / \mathrm{v}$ $\mathrm{HNO}_{3}$ solution. Samples were then rinsed in overflowing de-ionized water. Smart functionalized chromate conversion coatings, (SFCCCs) were formed by immersion in a bath containing a mixture of chromium trioxide $\mathrm{CrO}_{3}(10$ to $150 \mathrm{mM}), \mathrm{NaF}$ and a source of silicate or fluorosilicic acid (2 - $\left.20 \mathrm{mM}\right)$, and glycerol or tannin (1 $10 \mathrm{mM}$ ) at room temperature. A typical example of the coating solution is as given in Table 1. After the coatings were formed, the coated surfaces were dried and coated with lacquer. No final rinse in water was required after the application of SFCCC. SFCCC dried at a fast rate.

To evaluate the overall performance of SFCCCs, lacquer coated and pre-scratched coated aluminium samples as well as those conversion coated with SFCCCs were subjected to $100 \%$ relative humidity environment for 255 hours. Six samples each of variously treated aluminium specimens were tested. The cleaned aluminium specimens and those coated with lacquer, served as control. Prior to exposure and after exposure to high relative humidity, the specimens were examined visually and with the aid of an optical microscope with an attached camera.

Beyond the laboratory works, field applications of the formulated SFCCCs were performed at various factories in different parts of Nigeria.

\section{Results and Discussions}

A properly etched/de-smutted aluminium specimen is usually free from corrosion products although, it may carry occasional pits developed as a result of inter-metallic compound that intersects the surface of the substrate which dropped off during etching/de-smutting procedures.

To the naked eye, SFCCCs formed on aluminium by a 1-minute immersion in a $1 \mathrm{mM}$ of glycerol/tannin, 50 $\mathrm{mM} \mathrm{CrO}_{3}, 2 \mathrm{mM}$ fluorosilicic acid at pH 1.6 bath exhibited a greenish golden yellow integral surface layer that appeared continuous across the sample surface. This indicated coating formation on the metallic surfaces during the short treatment time.

From optical microscopy examinations, the SFCCC formed in and over pits that developed during degreasing treatments. The development and mechanism of chromate conversion coating on aluminium have been described by various authors [13]-[16] to involve the anodic activation of aluminium by fluoride species in the coating solution which is subsequently followed by cathodic reactions involving the reduction of $\mathrm{Cr}^{6+}$ species to $\mathrm{Cr}^{3+}$ hydrated compounds and hydrogen evolution. With increase in the interfacial $\mathrm{pH}, \mathrm{Cr}(\mathrm{OH})_{3}$ and/or $\mathrm{Cr}_{2} \mathrm{O}_{3}$, hydrated or otherwise are deposited on the substrate with additional adsorption and occlusion of $\mathrm{Cr}^{6+}$ species in the developing coating. However, with the present formulation the development of the coating is thought to

Table 1. Typical composition of smart functionalised chromate conversion coating solution.

\begin{tabular}{cc}
\hline Component & Amount $(\mathrm{g} / \mathrm{l})$ \\
\hline $\mathrm{CrO}_{3}$ & 50 \\
Fluorosilicic acid & 20 \\
Glycerol/tannin & 10 \\
Water & Remainder \\
\hline
\end{tabular}


partially follow the procedure described by Kendig et al. [12]. The tetrahedral structure described [17] in this instance, is formed in-situ in the coating solution. Stoichiometric equivalent of $\mathrm{Cr}^{6+}$ in the coating solution are reduced to $\mathrm{Cr}^{3+}$ on adding poly hydroxyl compounds, which are oxidized to the corresponding aldehydes. The aldehydes are thought to form complexes with $\mathrm{Cr}^{3+}$ tetrahedral structure unto which the labile $\mathrm{Cr}(\mathrm{VI})$ species are attached. On activation of aluminium substrate by fluoride species in the coating solution and with the cathodic hydrogen evolution reaction and subsequent increase in interfacial $\mathrm{pH}$, the tetrahedral structure reacts with the aluminium substrate to form an integral part of the substrate with elimination of water. Consequently, the coating dries rapidly on withdrawing the specimen from the coating solution. No final rinse with copious amount of water is required. However, since there are $\mathrm{Cr}^{6+}$ species in the coating solution, some may be reduced as additional cathodic reaction with subsequent deposition of $\mathrm{Cr}^{3+}$ compounds albeit as a minor part of the coating.

Damages, as a result of pitting corrosion and paint delamination were not observed on any of the samples coated with SFCCC after exposure in the humidity cabinet. Similar observations were recorded for the SFCCC coated specimens without a top coating of lacquer as displayed in Figure 1 which shows a pre-scratched region running diagonally in the macrograph with intact conversion coatings on adjacent sides.

Conversely, in Figure 2, incipient pits displayed as dark spots at the bottom of the macrograph, paint delamination and mounds of corrosion products under the lacquer as shown in the upper part of the macrograph, were observed on the untreated aluminium specimens with top coating of lacquer. Those specimens without a top lacquer coating showed similar features after exposure periods in the cabinet.

The differences in the spread of corrosion products and pitting corrosion observed visually and with the aid of optical microscope on the control samples and the coated samples were indications of the extent of corrosion protection provided by SFCCCs; For paint delamination and pitting to have been prevented from initiating on the surfaces of samples coated with SFCCC showed that, the spread of corrosion from the pre-scratched region was stifled by labile inhibitors present in the SFCCC. The results obtained for SFCCC coated for $60 \mathrm{~s}$ and bare aluminium specimens with and without top lacquer coatings, after 255 hrs of exposure in high relative humidity cabinet are as described and summarized in Table 2.

Results of exposure in service environments and in-factory assessments from aluminium color coating companies at different locations in Nigeria have indicated that, in the past three years the SFCCC has combined excellent performance with a reduced environmental footprint.

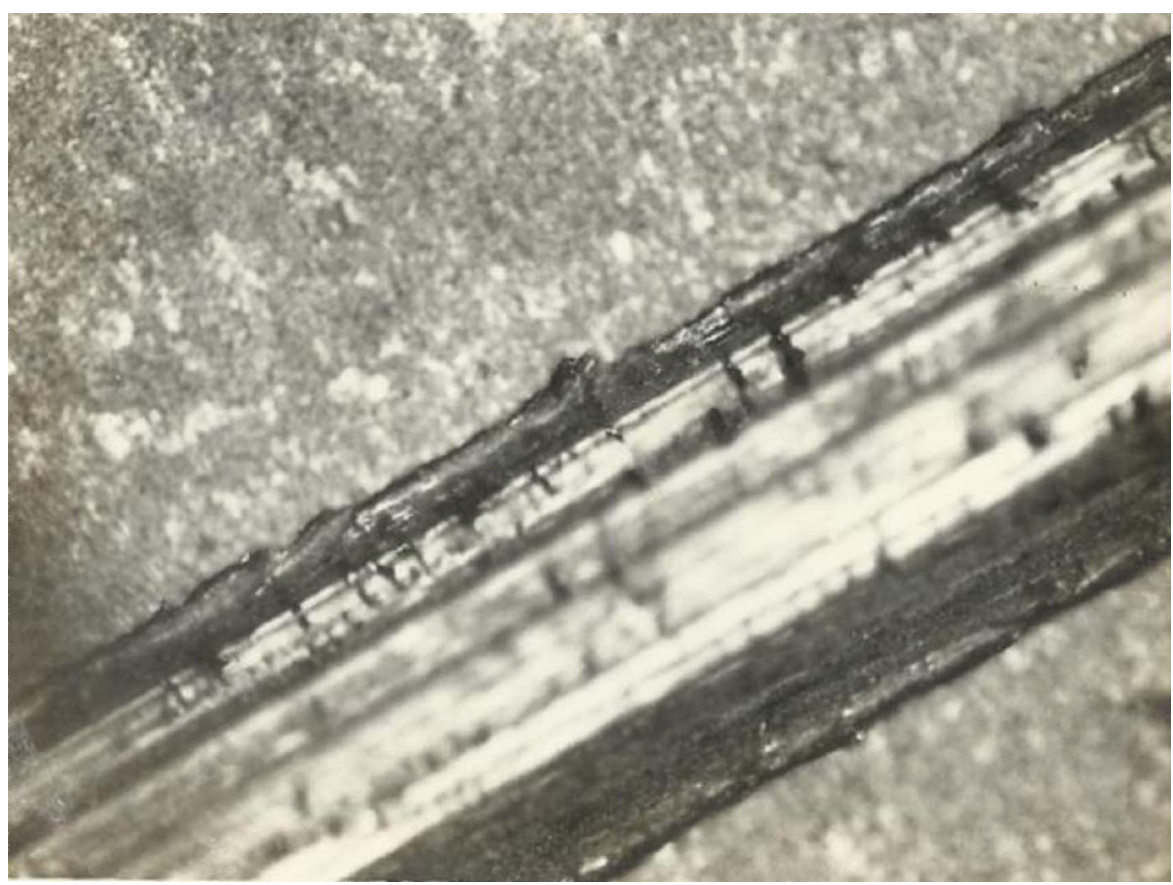

Figure 1. Optical photograph of a conversion coated aluminium with a top coating of lacquer after exposure to high humidity for 255 hours without paint delamination at the edge of a pre $=$ scratched region and no pitting corrosion. $\times 1000$. 


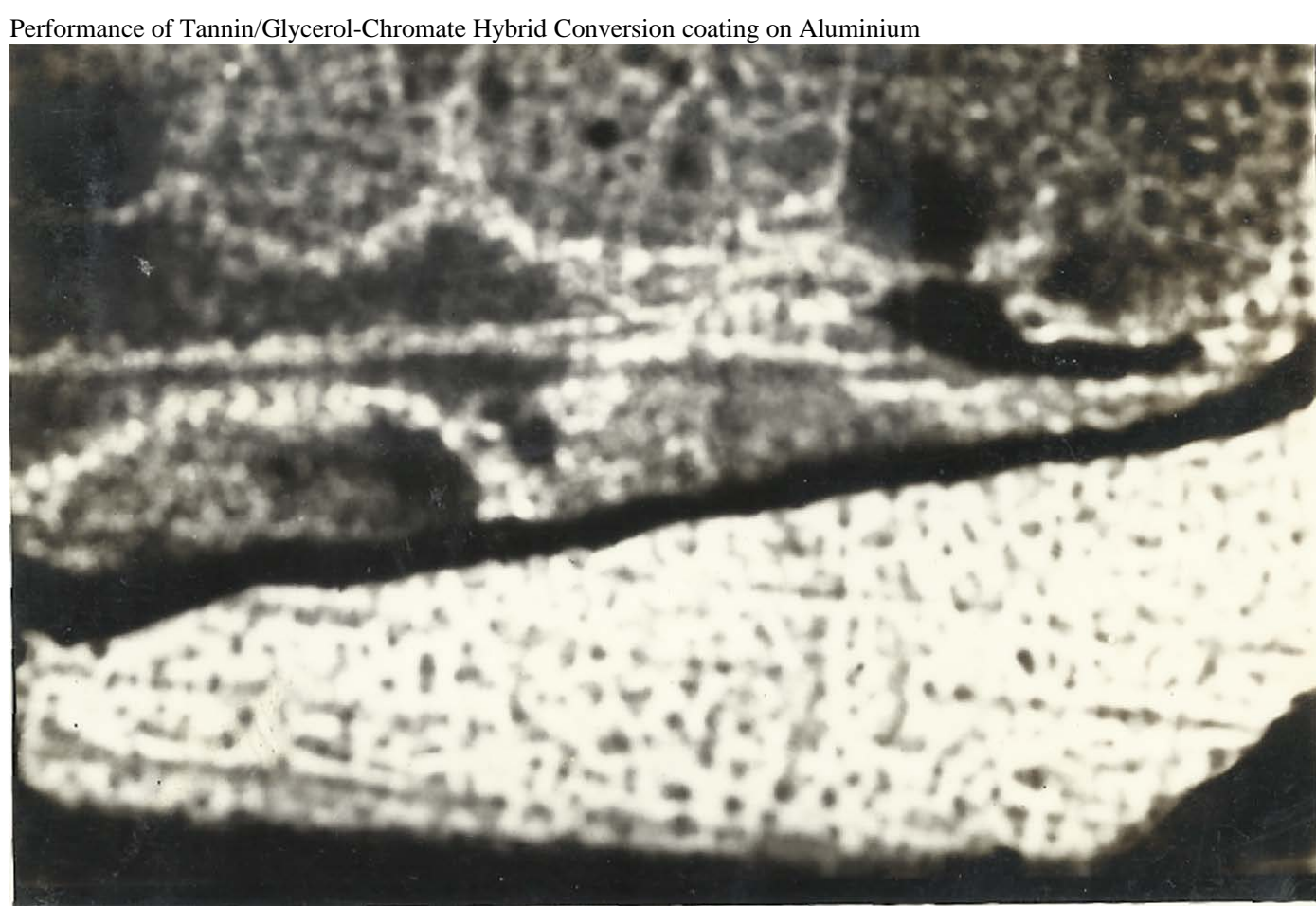

Figure 2. Optical photograph of lacquer coated aluminium specimen after exposure to high humidity for 255 hours showing paint delamination and incipient pitting corrosion at the edge of a pre-scratched region where lacquer had been lifted up as a result of paint delamination. $\times 1000$.

Table 2. Results of exposure test in high relative humidity cabinet.

\begin{tabular}{ll}
\hline \multicolumn{1}{c}{ Specimens } & \multicolumn{1}{c}{ Results } \\
\hline $\begin{array}{l}\text { 6 SFCCC coated without top coating of lacquer } \\
\text { and scratched to reveal the substrate. }\end{array}$ & No incipient pits and corrosion products observed. \\
$\begin{array}{l}\text { 6 SFCCC coated with top coating of lacquer } \\
\text { and scratched to reveal the substrate. }\end{array}$ & $\begin{array}{l}\text { No incipient pits observed within the scratched and } \\
\text { unscratched regions. Paint delamination was not observed. }\end{array}$ \\
6 Bare aluminium without top coating of lacquer. & $\begin{array}{l}\text { Incipient pits and mounds of corrosion products were } \\
\text { observed on the specimen. }\end{array}$ \\
$\begin{array}{l}6 \text { Bare aluminium with top coating of lacquer } \\
\text { and scratched to reveal the substrate. }\end{array}$ & Elaborate paint delamination and incipient pits were observed. \\
\hline
\end{tabular}

\section{Conclusions}

Functionalised chromate conversion coating chemical was formulated by adding a required quantity of locally available poly hydroxyl compounds such as tannin from Rhizofora racemosa and/or glycerol, a by-product of soap manufacturing to a chromate coating solution. The functionalised chemical was applied on metallic surfaces through a none-rinse process. Thus, effluent containing chromium VI species was eliminated in the processing of metals prior to application of organic finishes.

The coating prevented paint delamination and pits formation on the substrate exposed to high relative humidity. However, further studies are required to know the composition of the coating and further elucidate its mode of formation.

\section{Acknowledgements}

The author acknowledges National Universities Commission, Nigeria for the award of Linkages with Experts and Academics in Diaspora Scheme (LEADS), during which period a part of the research was carried out. We acknowledge the Vice Chancellor and Management of Institute of Petroleum Studies, University of Port Har- 
court, Rivers State, Nigeria for provision of facilities during the scheme. Also our gratitude goes to Dr Dokun Olayinka in Manchester, UK, for his support.

\section{References}

[1] Oki, M. and Wutche, N. (2004) Epoxidised Oil from the Seeds of Jatropha Plant/n-Butyl Amine as Corrosion Inhibitor for Aluminium. Journal of Corrosion Science and Technology, 1, 72-75.

[2] Chaieb, E., Bouyanzer, A., Hammouti, B. and Berrabah, M. (2009) Limonene as Green Inhibitor for Steel Corrosion in HCl Solution. Acta Physico-Chimica Sinica, 25, 1254-1258.

[3] Otaigbe, J.O.E. (2005) Effects of Experimental Variables on the Degree of Epoxidation of Cashew Nut Oil and Cashew Nut Shell Oil Using Clay-Supported Hydrogen Peroxide. Global Journal of Pure and Applied Sciences, 11, 505-510.

[4] Oki, M., Alaka, C.O., Charles, E. and Oki, T.K. (2011) Corrosion Inhibition of Mild Steel in HCl by Rhizophora Racemosa. Materials Sciences and Applications, 2, 592-595. http://dx.doi.org/10.4236/msa.2011.26079

[5] Oki, M., Otaigbe, J.O.E., Oki, T.K. and Otikor, S. (2014) Corrosion Inhibition of Aluminium in HCl by Amine Modified Epoxy Resin. Journal of Materials, 2013, Article ID: 479728.

[6] El-Etre, A.Y., Abdallah, M. and El-Tantawy, Z.E. (2005) Corrosion Inhibition of Some Metals Using Lawsonia Extract. Corrosion Science, 47, 385-395. http://dx.doi.org/10.1016/j.corsci.2004.06.006

[7] Amin, M.A., Abd El-Rehim, S.S., El-Sherbini, E.E.F. and Hazzazi, O.A. (2009) Polyacrylic Acid as a Corrosion Inhibitor for Aluminium in Weakly Alkaline Solutions. Part I: Weight Loss, Polarization, Impedance EFM and EDX Studies. Corrosion Science, 51, 658-667. http://dx.doi.org/10.1016/j.corsci.2008.12.008

[8] Saji, V.S. (2011) Contemporary Developments in Corrosion Inhibitors-Review of Patents. Recent Patents on Corrosion Science, 1, 63-67. http://dx.doi.org/10.2174/2210683911101010063

[9] Zhu, D. and Van-Ooij, W.J. (2008) Addition of Silanes to Coating Compositions. US Patent 026151.

[10] Gammel, F., Hack, T. and Dominik, W.J. (2009) Anticorrosive Paint for Metal Substrates Containing Polymer-Encapsulated Corrosion Inhibitors. Patent DE102008003392.

[11] Boocock, S. (2009) Non-Chromate Corrosion Inhibitor Formulas Based on Highly Crystalline Hydrotalcite Analogs. Patent WO039095.

[12] Kendig, M.W. and Buchheit, R.G. (2003) Corrosion Inhibition of Aluminium and Aluminium Alloys by Soluble Chromates, Chromate Coatings, and Chromate-Free Coatings. Corrosion, 59, 379-400. http://dx.doi.org/10.5006/1.3277570

[13] Oki, M. (1985) Conversion Coatings on Aluminium. Ph.D. Thesis, University of Manchester, UK.

[14] Brown, G.M., Shimuzu, K., Kobayashi, K., Thompson, G.E. and Wood, G.C. (1992) The Morphology, Structure, and Mechanism of Growth of Chemical Conversion Coatings on Aluminum. Corrosion Science, 33, 1371-1382. http://dx.doi.org/10.1016/0010-938X(92)90178-6

[15] Oki, M., Oki, T.K. and Charles, E. (2012) Chromate and Chromate Phosphate Conversion Coatings on Aluminium. Arabian Journal for Science and Engineering, 37, 59-64. http://dx.doi.org/10.1007/s13369-011-0157-2

[16] Oki, M. (2013) Microstructural and Compositional Characterisation of Chromate Pretreatment on Aluminium. ISRN Materials Science, 2013, Article ID: 572379. http://dx.doi.org/10.1155/2013/572379

[17] Henry, M., Jolivet, J.P. and Livage, L. (1992) Aqueous Chemistry of Metal Cations: Hydrolysis Condensation, and Complexation. In: Structure and Bonding, Springer-Verlag, Berlin, 155. http://dx.doi.org/10.1007/bfb0036968 